\title{
Study on Integrated Control of Active Front Steering and Direct Yaw Moment Based on Vehicle Lateral Velocity Estimation
}

\author{
Tao Sun, ${ }^{1}$ Hao Guo, ${ }^{1}$ Jian-yong Cao, ${ }^{2}$ Ling-jiang Chai, ${ }^{1}$ and Yue-dong Sun ${ }^{1}$ \\ ${ }^{1}$ University of Shanghai for Science and Technology, School of Mechanical Engineering, Institute of Automotive Engineering, \\ Shanghai 200093, China \\ ${ }^{2}$ National Center of Supervision and Inspection on Motor Vehicle Products Quality, Shanghai 201805, China
}

Correspondence should be addressed to Tao Sun; tao_sun531@163.com

Received 23 January 2013; Accepted 11 April 2013

Academic Editor: Tsung-Chih Lin

Copyright (C) 2013 Tao Sun et al. This is an open access article distributed under the Creative Commons Attribution License, which permits unrestricted use, distribution, and reproduction in any medium, provided the original work is properly cited.

Considering the vehicle lateral velocity is difficult to be measured at integration of chassis control in configuration of production vehicle, this study presents the vehicle lateral velocity estimation based on the extended Kalman filtering with the standard sensor information. The fuzzy control algorithm is proposed to integrate direct yaw moment control and active front steering with lateral velocity estimation. The integration controller produces direct yaw moment and front wheel angle compensation to control yaw rate and sideslip angle, which makes the actual vehicle yaw rate and sideslip angle follow desirable yaw rate and desirable sideslip angle. The simulation results show vehicle handling and stability are enhanced under different driving cycles by the proposed algorithm.

\section{Introduction}

To improve the handling and stability of the vehicle, many active safety systems are applied to the vehicle, such as active front steering (AFS), antilock braking system (ABS), traction control system (TCS), and electronic stability program (ESP) [1]. However, these systems are designed independently of each other for improving specific vehicle performance, so their functions are limited due to the nonlinearity of tyre forces and the essential dynamic coupling between these systems [2]. Therefore, in order to optimize vehicle performance, the integration of these active control systems has currently become a research focus on vehicle dynamics and control fields [3-6]. Furthermore, estimation of vehicle states and parameters is vital for the integration of chassis function related to vehicle stability control, in which vehicle lateral and yaw dynamics control is dependent on the accurate lateral velocity or the sideslip angle estimation to cope with high cost, signal degradation in sensor configuration of production vehicles $[7,8]$. Therefore, the estimation of vehicle lateral velocity based on standard vehicle input/output signals is presented in this paper, in which a fuzzy logic algorithm is designed with two inputs and two outputs based on the integration of AFS and direct yaw moment control (DYC) to enhance the vehicle stability.

This paper is organized as follows. Section 2 addresses the vehicle dynamics model and a nonlinear tyre model. Section 3 designs the lateral velocity observer in detail, including selecting sensor signals, estimation model, and algorithm. Section 4 presents the proposed control system. The computer simulation results are presented and the proposed control system is compared with the individual control cases in Section 5. Finally, Section 6 gives the conclusions of the research.

\section{Vehicle and Tyre Models}

2.1. 8DOF Vehicle Model for Simulation. The vehicle dynamics model used in this research is shown in Figure 1. The model considered for simulation consists of 8 degrees of freedom (DOF), which include longitudinal and lateral motions, yaw motion, and body roll motion of the vehicle as well as the rotational dynamics of the four wheels. Here, the vertical and pitch motions are neglected. However, the load transfers, both longitudinally and laterally, are taken into account in the model. 
The governing equations of motion can be expressed as follows [9]:

$$
\begin{gathered}
m\left(\dot{v}_{x}-v_{y} \gamma\right)=F_{x f l}+F_{x f r}+F_{x r l}+F_{x r r}, \\
m\left(\dot{v}_{y}+v_{x} \gamma\right)=F_{y f l}+F_{y f r}+F_{y r l}+F_{y r r}+m_{s} e \dot{p}, \\
I_{z} \dot{\gamma}-I_{x z} \dot{p}=a\left(F_{y f l}+F_{y f r}\right)-b\left(F_{y r l}+F_{y r r}\right) \\
+0.5 T\left(F_{x f r}+F_{x r r}-F_{x f l}-F_{x r l}\right), \\
I_{x} \dot{p}=m_{s} e \dot{v}_{x}+m_{s} e v_{y} \gamma+m_{s} g e \phi \\
-K_{\phi} \phi-C_{\phi} \dot{\phi}+I_{x z} \dot{r}, \\
I_{w} \dot{\omega}_{i}=-F_{x i} R+T_{b i} \quad i=(f l, f r, r l, r r) .
\end{gathered}
$$

In the above equations, $v_{x}$ stands for the longitudinal vehicle velocity, $v_{y}$ the lateral vehicle velocity, $\gamma$ the yaw rate, $\phi$ the roll angle, and $p$ the roll rate. $m$ denotes the total mass of the vehicle, $m_{s}$ the sprung mass, $F_{x i}$ and $F_{y i}$ the tyre force components in the $x$ and $y$ directions, respectively, $a$ and $b$ distances from the centre of gravity to the front and rear axles, respectively, and $e$ the distance between the center of gravity of the sprung mass and the roll centre. $T$ is the track width (assuming that the front track width equals the rear track width). $I_{z}$ and $I_{x}$ are yaw inertia moment and roll inertia moment, respectively, $I_{x z}$ sprung mass product of inertia, $I_{w}$ wheel moment of inertia, $R$ wheel radius, and $T_{b i}$ brake torque applied to the $i$ wheel. $K_{\phi}$ and $C_{\phi}$ are roll stiffness and roll damping, respectively.

The tyre force $F_{x i}$ and $F_{y i}$ can be calculated through the coordinate transformation;

$$
\left[\begin{array}{c}
F_{x i} \\
F_{y i}
\end{array}\right]=\left[\begin{array}{cc}
\cos \delta_{i} & -\sin \delta_{i} \\
\sin \delta_{i} & \cos \delta_{i}
\end{array}\right]\left[\begin{array}{l}
F_{t i} \\
F_{s i}
\end{array}\right] \quad i=f l, f r, r l, r r .
$$

Considering the load transfers caused by the longitudinal and lateral accelerations, the normal load for each wheel can be expressed as follows:

$$
\begin{aligned}
F_{z f l}= & \frac{m g}{2 L}\left[b-\frac{\left(\dot{v}_{x}-v_{y} \gamma\right) h}{g}\right] \\
& +\frac{m a_{y} h}{T} K_{R}-\frac{K_{R} m_{s} g e \sin \phi}{T}, \\
F_{z f r}= & \frac{m g}{2 L}\left[b-\frac{\left(\dot{v}_{x}-v_{y} \gamma\right) h}{g}\right]-\frac{m a_{y} h}{T} K_{R} \\
& \left.+\frac{K_{R} m_{s} g e \sin \phi}{T}, \quad \frac{\left(\dot{v}_{x}-v_{y} \gamma\right) h}{g}\right]+\frac{m a_{y} h}{T}\left(1-K_{R}\right) \\
F_{z r l}= & \frac{m g}{2 L}\left[a+\frac{\left(1-K_{R}\right) m_{s} g e \sin \phi}{T},\right.
\end{aligned}
$$

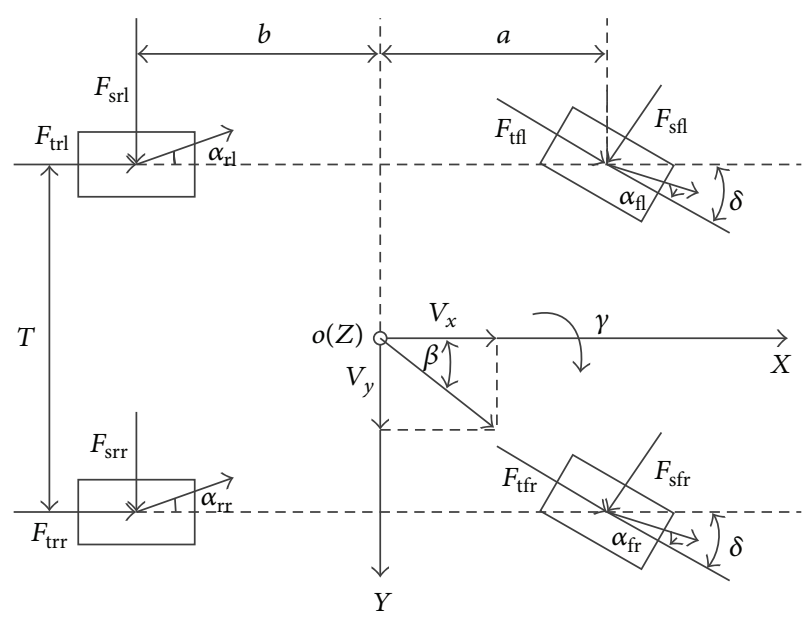

Figure 1: 8DOF vehicle model.

$$
\begin{aligned}
F_{z r r}= & \frac{m g}{2 L}\left[a+\frac{\left(\dot{v}_{x}-v_{y} \gamma\right) h}{g}\right]-\frac{m a_{y} h}{T}\left(1-K_{R}\right) \\
& +\frac{\left(1-K_{R}\right) m_{s} g e \sin \phi}{T},
\end{aligned}
$$

where $L=a+b$ is wheelbase, $K_{R}=K_{f} /\left(K_{f}+K_{r}\right), K_{f}$ and $K_{r}$ are the front and rear roll stiffness, and $h$ is the height of center of gravity.

2.2. Dugoff Tyre Model. The Dugoff model [10] synthesizes all the tyre property parameters into several constants $C_{i}, C_{\alpha}$, and $\lambda$, referred to as the longitudinal, cornering stiffness, and slip rate of the tyre. In the proposed method, the longitudinal and lateral tyre forces can be acquired from the tyre model for the estimation of vehicle lateral velocity further.

According to the $8 \mathrm{DOF}$ vehicle model, each wheel has an independent slip angel:

$$
\begin{aligned}
& \alpha_{f l}=\delta-\arctan \left(\frac{v_{y}+a \gamma}{v_{x}-0.5 T \gamma}\right), \\
& \alpha_{f r}=\delta-\arctan \left(\frac{v_{y}+a \gamma}{v_{x}-0.5 T \gamma}\right), \\
& \alpha_{r l}=\delta+\arctan \left(\frac{b \gamma-v_{y}}{v_{x}-0.5 T \gamma}\right), \\
& \alpha_{r r}=\delta+\arctan \left(\frac{b \gamma-v_{y}}{v_{x}-0.5 T \gamma}\right) .
\end{aligned}
$$

Moreover, the longitudinal tyre slip is defined as follows:

$$
\sigma_{i}=\left\{\begin{array}{ll}
\frac{v_{x i}-R W_{i}}{v_{x i}} & R W_{i}<v_{x i} \\
\frac{v_{x i}-R W_{i}}{R W_{i}} & R W_{i} \geq v_{x i}
\end{array} \quad i=f l, f r, r l, r r,\right.
$$




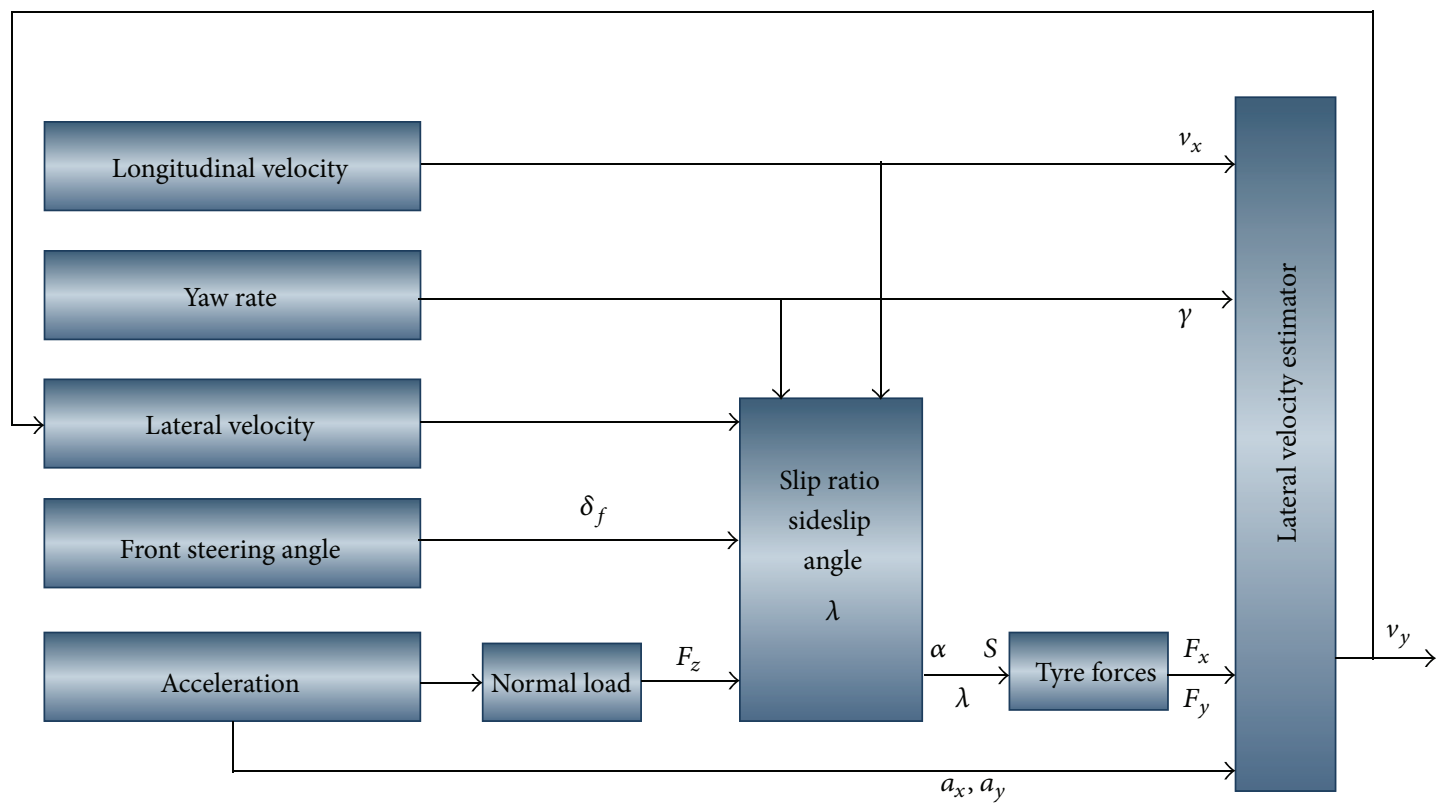

FIgURE 2: Structure of lateral velocity observer.

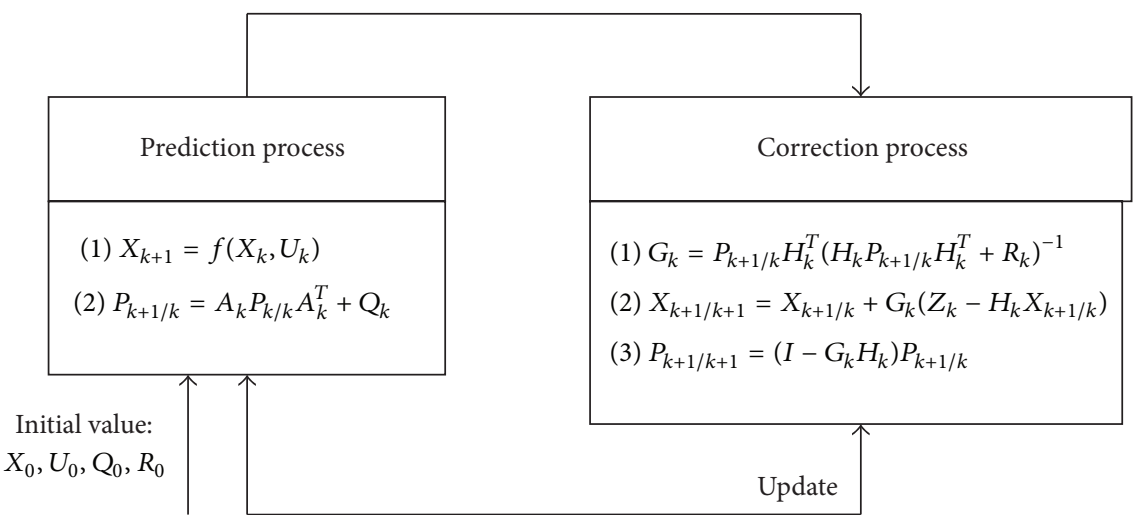

FIGURE 3: Block diagram of EKF algorithm.

where $v_{x_{i}}$ are the velocity components in the wheel plane:

$$
\begin{aligned}
& v_{x f l}=\left(v_{x}-0.5 T \gamma\right) \cos \delta+\left(v_{y}+a \gamma\right) \sin \delta, \\
& v_{x f r}=\left(v_{x}+0.5 T \gamma\right) \cos \delta+\left(v_{y}+a \gamma\right) \sin \delta, \\
& v_{x r l}=\left(v_{x}-0.5 T \gamma\right) \cos \delta-\left(b \gamma-v_{y}\right) \sin \delta, \\
& v_{x r r}=\left(v_{x}+0.5 T \gamma\right) \cos \delta-\left(b \gamma-v_{y}\right) \sin \delta .
\end{aligned}
$$

The lateral and longitudinal forces of the tyre, neglecting the self-aligning moment, are determined by the following equations:

$$
\begin{gathered}
F_{x i}=\frac{C_{i} \sigma_{i} f(\lambda)}{1+\sigma_{i}} \\
F_{y i}=\frac{C_{\alpha} \tan \alpha_{i} f(\lambda)}{1+\sigma_{i}}
\end{gathered}
$$

with

$$
\begin{gathered}
\lambda_{i}=\frac{\mu F_{z i}\left[1-\varepsilon_{r} v_{x i} \sqrt{\sigma_{i}^{2}+\tan ^{2} \alpha_{i}}\right]\left(1+\sigma_{i}\right)}{2 \sqrt{C_{i}^{2} \sigma_{i}^{2}+C_{\alpha}^{2} \tan ^{2} \alpha_{i}}}, \\
f(\lambda)= \begin{cases}\lambda_{i}\left(2-\lambda_{i}\right) & \lambda_{i}<1 \\
1 & \lambda_{i} \geq 1,\end{cases}
\end{gathered}
$$

where $F_{y i}$ is the lateral force, $F_{x i}$ is the longitudinal force, $F_{z i}$ is the normal force for $i$-wheel, $\varepsilon_{r}$ is road adhesion reduction factor, and $\mu$ is nominal friction coefficient between tyre and ground. $C_{i}$ And $C_{\alpha}$ are longitudinal stiffness and cornering stiffness, respectively.

\section{Lateral Vehicle Velocity Estimators}

Vehicle state estimation problem could be summarized in three points: obtaining existing input or output sensor signal, 


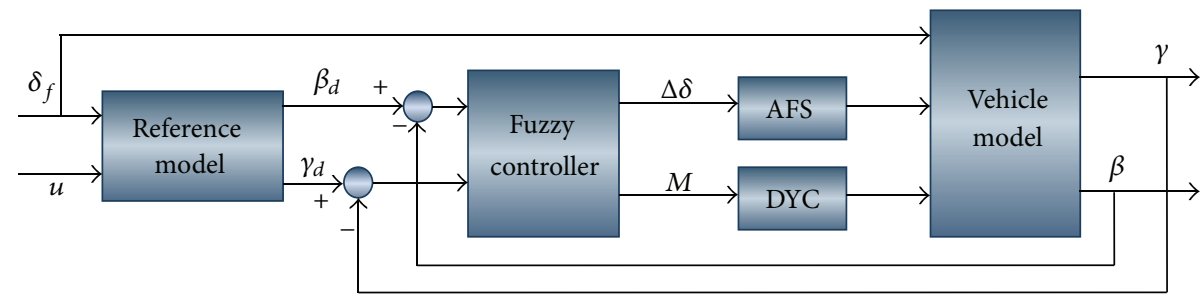

FIgURE 4: Control structure of AFS + DYC system.

selecting state estimation model, and estimating algorithm [11].

3.1. Selecting Sensor Signals. Selecting sensor signals known is very important. Because the signals and estimation algorithm will combine, the feasibility, convenience, and applicability are considered among them. Block diagram is as shown in Figure 2.

3.2. Description of Vehicle Model. Consider the following simplified two freedom degrees vehicle lateral dynamic model with lateral and yaw motions. It is described by

$$
\begin{gathered}
m\left(\dot{v}_{y}+v_{x} \gamma\right)=F_{y f l}+F_{y f r}+F_{y r l}+F_{y r r}, \\
I_{z} \dot{\gamma}=a\left(F_{y f l}+F_{y f r}\right)-b\left(F_{y r l}+F_{y r r}\right) \\
\quad+0.5 T\left(F_{x f r}+F_{x r r}-F_{x f l}-F_{x r l}\right) .
\end{gathered}
$$

In the above equation, the meaning of symbols is the same as Section 2.1. From the equation, it can be seen that the model is simple and the complexity of state observer design is simplified.

3.3. Extended Kalman Filter. Most Kalman filters can be regarded as virtual sensors because with the aid of a mathematical model and particular measurement signals, unknown states can be estimated [12]. The state estimator proposed in this paper is based on the Kalman filtering technique, which is a widely used conceptual two-stage prediction/correction approach that has found application in a variety of areas. A powerful extension, developed for state estimation in nonlinear systems, is the so-called extended Kalman filter (EKF), in which the state equations are linearized at each operation point [13]. The main concept is similar to the standard KF.

In general, a nonlinear EKF system can be formulated as follows:

$$
\begin{aligned}
\frac{d}{d t} X(t) & =f(X(t), U(t))+\Gamma(t) w_{t}, \\
Z(t) & =H(X(t), U(t))+v(t) .
\end{aligned}
$$

The above two equations are discretized; the new expression is as follows:

$$
\begin{gathered}
X_{k+1}=f\left(X_{k}, U_{k}\right)+W_{k}, \\
Z_{k}=h\left(X_{k}, U_{k}\right)+V_{k},
\end{gathered}
$$
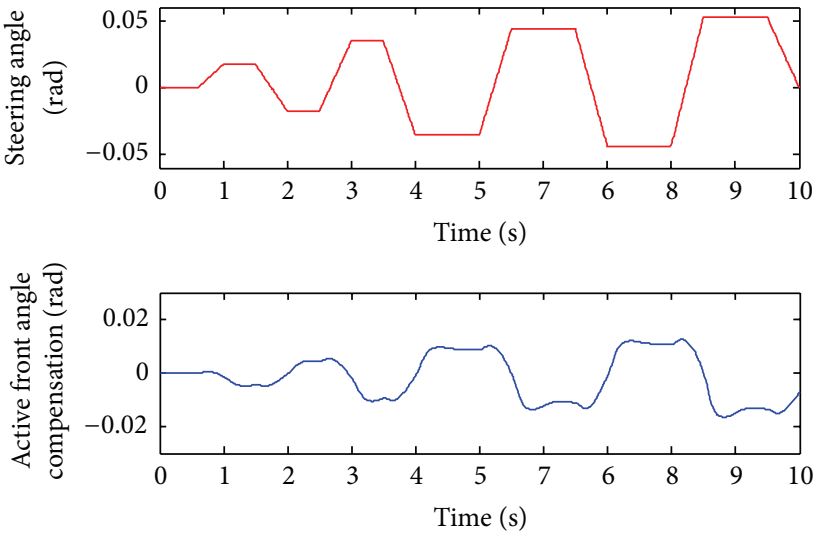

FIGURE 5: Slalom maneuver input angle and active front angle compensation.

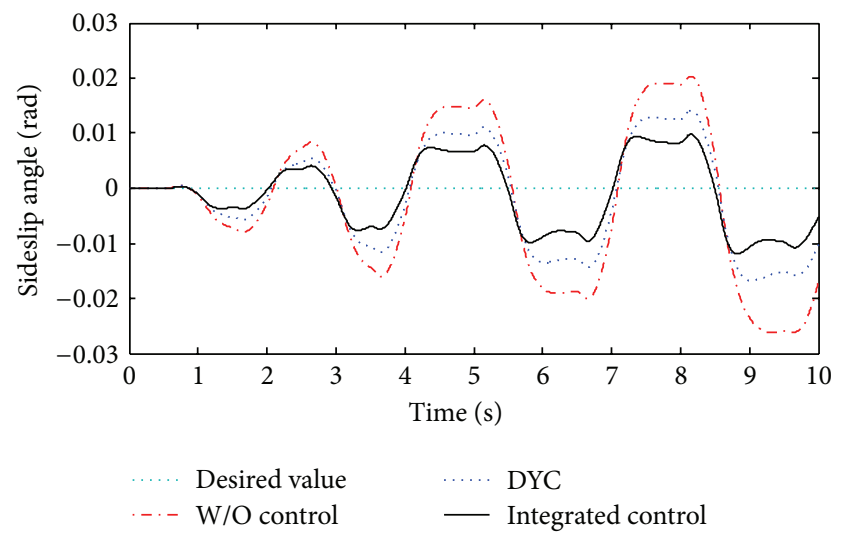

FIGURE 6: Sideslip angle responses.

where system state is $X_{k}$ for $k$ time, system input is $U_{k}$ for $k$ time, with $W_{k}$ and $V_{k}$ being the process noise and output noise, respectively. $Z_{k}$ is estimation value.

Extended Kalman filtering (EKF) algorithm process includes prediction and correction of two parts. Block diagram for EKF is as shown in Figure 3.

Where $G_{k}$ is the estimation gain matrix, $P_{k+1 / k}$ is the estimate error covariance matrix. $R_{k}$ and $Q_{k}$ are, respectively, the measurement covariance matrix and the process covariance matrix. $R_{k}$ and $Q_{k}$ are assumed to be constant and diagonal matrix; the off-diagonal elements are set to 0 . System error and measurement noise submit to Gaussian distribution and 


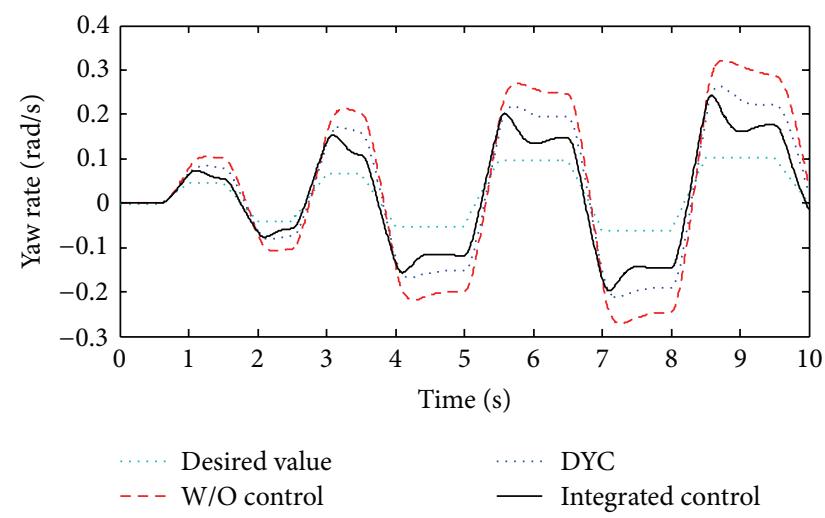

Figure 7: Yaw rate responses.

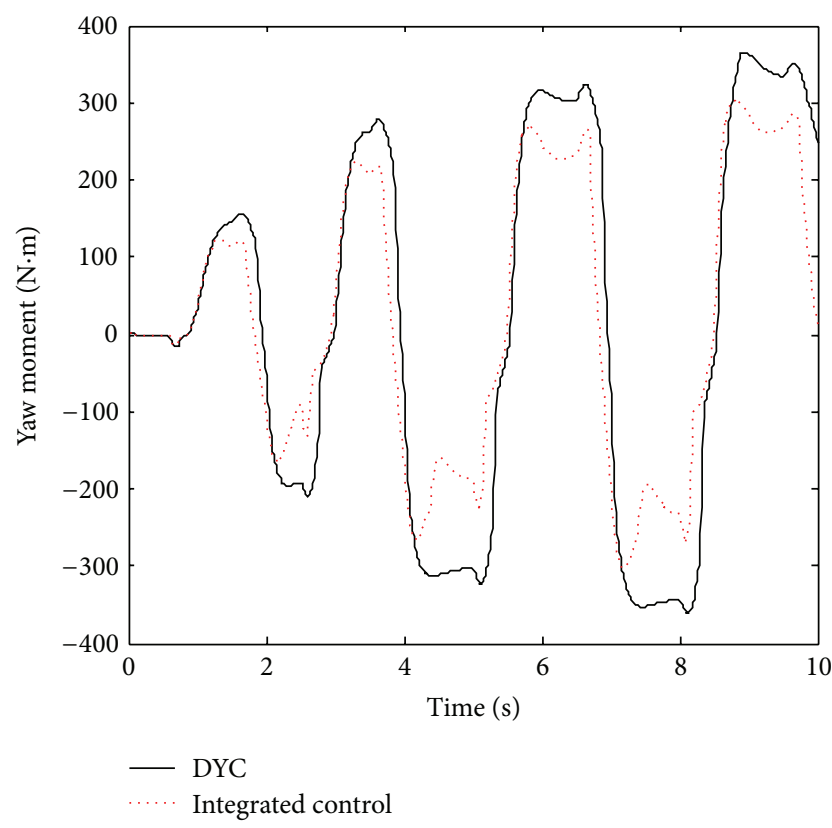

Figure 8: Yaw control moment.

the value of mean is zero. That means that both $R_{k}$ and $Q_{k}$ are supposed uncorrelated.

\section{Controller Design}

In order to improve vehicle handling and stability, fuzzy logic controller for AFS and DYC is designed based on 8DOF. The scheme is as shown in Figure 4.

4.1. Reference Vehicle Model. In this paper the desired model is assumed as the following response model. The yaw rate response to the steering wheel is the first-order delay system. Therefore the desired model can be described as follows [14]:

$$
\dot{X}_{d}=A_{d} X_{d}+E_{d} \delta_{f},
$$

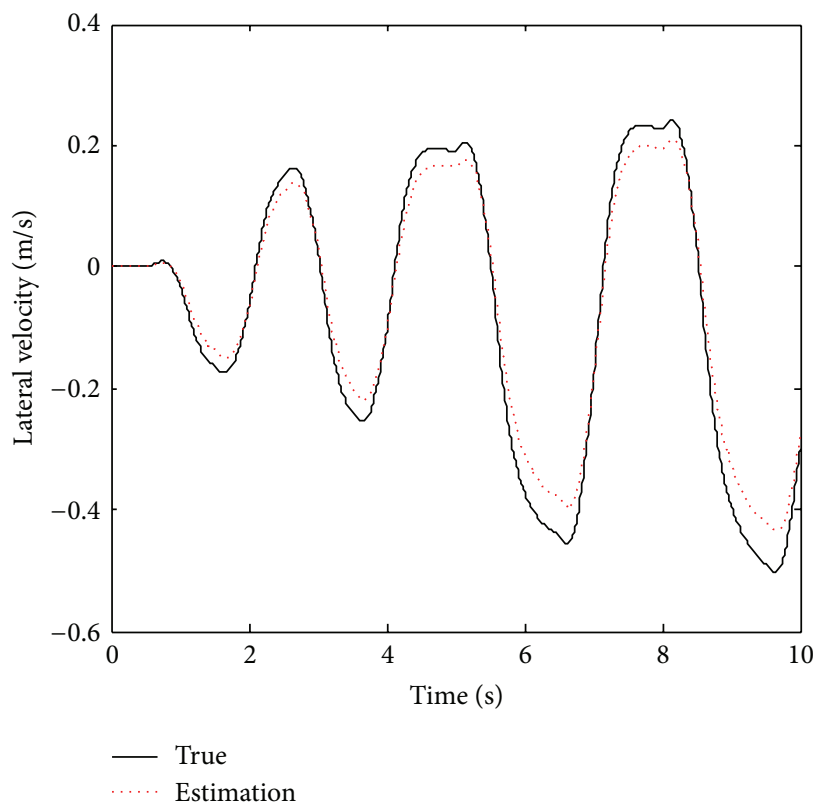

FIGURE 9: EKF observed value.

where $A_{d}=\left[\begin{array}{cc}0 & 0 \\ 0 & -1 / \tau\end{array}\right], E_{d}=\left[\begin{array}{c}0 \\ k / \tau\end{array}\right]$,

$$
\begin{gathered}
k=\frac{v_{x}}{a+m a b v_{x}^{2} /\left(2 C_{f} a(a+b)\right)}, \\
\tau=\frac{I_{z} v_{x}}{2 C_{f} a(a+b)+m b v_{x}^{2}} .
\end{gathered}
$$

4.2. Fuzzy Logic Control. A fuzzy control system can be usually divided into three parts [15]: part 1 , fuzzification; part 2, fuzzy rules and inference; part 3, defuzzification. In this paper, a fuzzy logic controller with two inputs and two outputs is developed.

Part 1: fuzzification two input variables for the fuzzy logic control are the error between the actual vehicle sideslip angle and the desired sideslip angle, and the error between the actual yaw rate and the desired yaw rate:

$$
\begin{gathered}
\Delta \beta=\beta-\beta_{d}, \\
\Delta \gamma=\gamma-\gamma_{d} .
\end{gathered}
$$

The output variables are the front steering compensation angle $\Delta \delta$ and the corrective yaw moment $M_{z}$.

The input variables can be fuzzified into seven fuzzy sets: PB (positive big), PM (positive medium), PS (positive small), ZE (zero), NS (negative small), NM (negative medium), and NB (negative big). Similarly, the output variables are fuzzified into nine fuzzy sets: $\{P V B, P B, P M, P S, Z E$, NS, NM, NB, NVB\}; PVB and NVB are positive very big and negative very big, respectively. For simplicity, a triangular membership function is adopted to convert these inputs and output variables into linguistic control variables in this study.

The fuzzy controller uses the Mamdani fuzzy inference system, which is characterized by the following fuzzy rule schema. It is as shown in Table 1. 

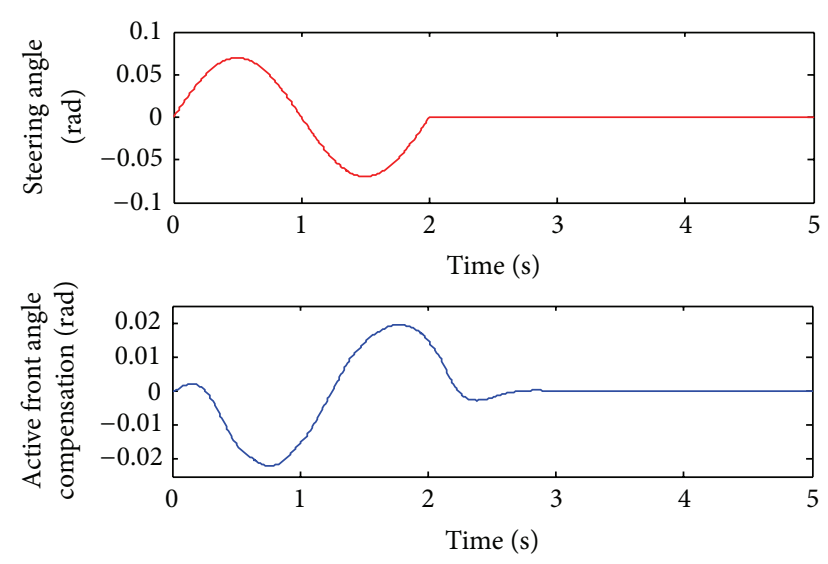

Figure 10: Sine maneuver input angle and active front angle compensation.

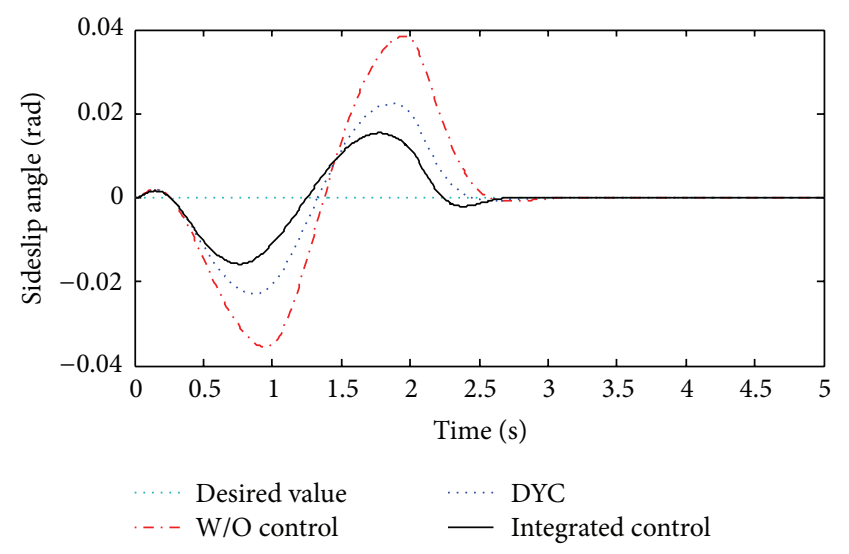

FIGURE 11: Sideslip angle responses.

\section{Simulation Results and Analysis}

The presented control system is evaluated on $8 \mathrm{DOF}$ nonlinear vehicle model platform through several computer simulations. Two different maneuvers are considered here. The first maneuver is related to the sinusoidal with increasing amplitude steering input, which is often used in the vehicle handling performance test, and we call this maneuver slalom in the sequel [16]. The second one is a single lane change maneuver with a single sinusoidal steering input. In the process of simulations, the responses of a vehicle with the proposed integrated control system are compared with those of a vehicle with an individual control system, DYC, and without control. The vehicle parameters employed for computer simulations are given in Table 2 [17].

5.1. Slalom Maneuver. In the simulation, the initial longitudinal velocity is $30 \mathrm{~m} / \mathrm{s}$ and friction coefficient between tyre and $\operatorname{road} \mu$ is 0.5 . The steering input signal with a slalom maneuver is shown in Figure 5. The input angle increases gradually and the maximum value is $3^{\circ}$. Figure 5 is front wheel angle compensation for integrated control vehicle. Figure 6 illustrates the comparison of vehicle responses with different control

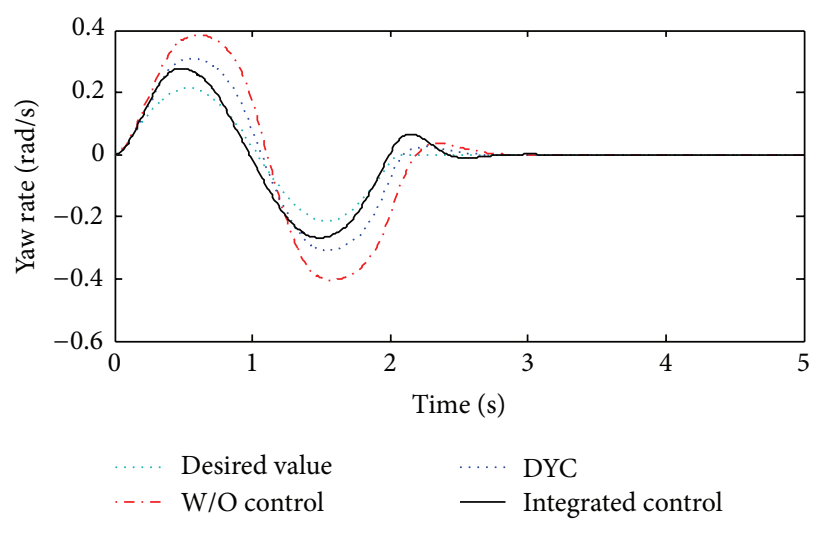

FIGURE 12: Yaw rate responses.

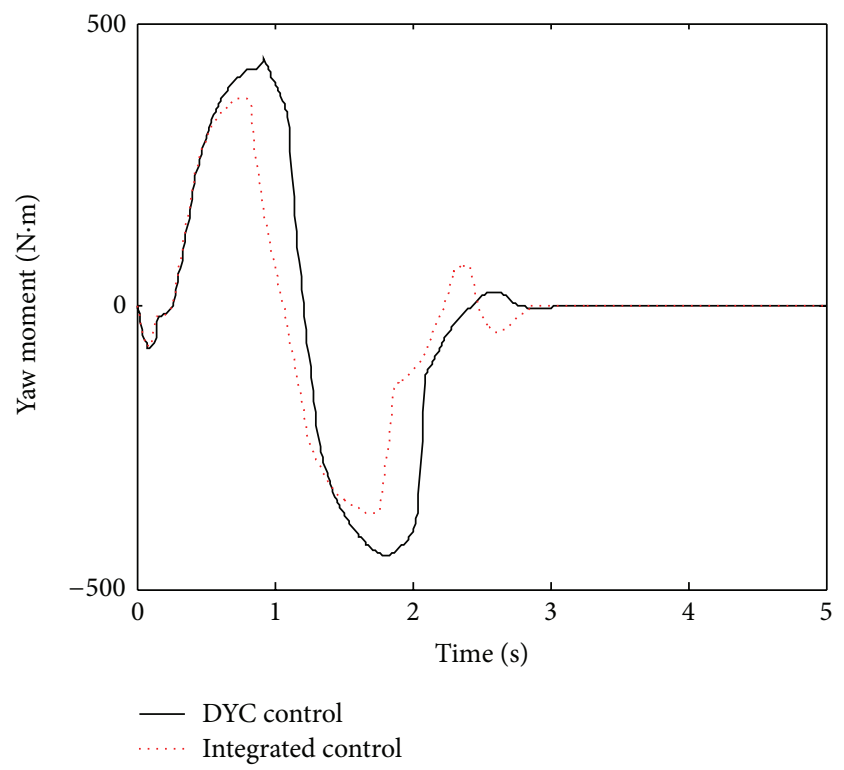

FIgURE 13: Yaw control moment.

systems. It can be seen that, compared with the uncontrolled vehicle and only DYC, the sideslip angle responses of vehicles with control systems have been improved. The sideslip angle is suppressed effectively. As shown in Figure 7, the yaw rate response of the vehicle with the proposed integrated control system can track the desired yaw rate more satisfactorily than the individual control system DYC and without control. From the simulation results, it can be concluded that the vehicle handling and stability are improved. From Figure 8, it can be seen that the proposed integrated control system needs smaller yaw control moment in contrast with DYC. The smaller the control moment is needed, the less vehicle velocity is affected. From Figure 8, it can be concluded that the integrated control system is able to achieve better stability in the smaller control energy. It can be seen that, from Figure 9, the lateral velocity estimated is close to true value. It verifies the effectiveness of the proposed estimator, and at the same time its value meets the needs of vehicle stability control system designed. 
TABLE 1: Rule base.

\begin{tabular}{|c|c|c|c|}
\hline$e(\beta)$ & $e(\gamma)$ & $\Delta \delta$ & $M$ \\
\hline NB & $\mathrm{PB}$ & $\mathrm{PB}$ & NVB \\
\hline NM & $\mathrm{PB}$ & PM & NVB \\
\hline NS & $\mathrm{PB}$ & NM & NVB \\
\hline $\mathrm{ZE}$ & $\mathrm{PB}$ & ZE & NB \\
\hline PS & $\mathrm{PB}$ & NM & NVB \\
\hline $\mathrm{PM}$ & $\mathrm{PB}$ & NVB & NVB \\
\hline PB & $\mathrm{PB}$ & NVB & NVB \\
\hline NB & $\mathrm{PM}$ & PM & NB \\
\hline NM & $\mathrm{PM}$ & PS & NB \\
\hline NS & $\mathrm{PM}$ & NS & NB \\
\hline $\mathrm{ZE}$ & $\mathrm{PM}$ & $\mathrm{ZE}$ & $\mathrm{NM}$ \\
\hline PS & $\mathrm{PM}$ & NS & NB \\
\hline $\mathrm{PM}$ & $\mathrm{PM}$ & NB & NB \\
\hline PB & $\mathrm{PM}$ & NVB & NB \\
\hline NB & PS & PS & NB \\
\hline NM & PS & PS & $\mathrm{NM}$ \\
\hline $\mathrm{PB}$ & NB & NM & PVB \\
\hline NS & PS & ZE & $\mathrm{NM}$ \\
\hline $\mathrm{ZE}$ & PS & $\mathrm{ZE}$ & NS \\
\hline PS & PS & NM & PS \\
\hline $\mathrm{PM}$ & PS & NB & NS \\
\hline $\mathrm{PB}$ & PS & NM & NS \\
\hline NB & $\mathrm{ZE}$ & PVB & $\mathrm{ZE}$ \\
\hline NM & ZE & $\mathrm{PB}$ & ZE \\
\hline NS & $\mathrm{ZE}$ & $\mathrm{PM}$ & NS \\
\hline $\mathrm{ZE}$ & ZE & $\mathrm{ZE}$ & $\mathrm{ZE}$ \\
\hline PS & ZE & NM & PM \\
\hline $\mathrm{PM}$ & $\mathrm{ZE}$ & NB & $\mathrm{ZE}$ \\
\hline $\mathrm{PB}$ & ZE & NVB & $\mathrm{ZE}$ \\
\hline NB & NS & PM & PS \\
\hline NM & NS & $\mathrm{PB}$ & PS \\
\hline NS & NS & PM & NS \\
\hline $\mathrm{ZE}$ & NS & $\mathrm{ZE}$ & $\mathrm{ZE}$ \\
\hline PS & NS & $\mathrm{ZE}$ & PM \\
\hline $\mathrm{PM}$ & NS & NS & PM \\
\hline $\mathrm{PB}$ & NS & NS & $\mathrm{PB}$ \\
\hline NB & $\mathrm{NM}$ & PVB & $\mathrm{PB}$ \\
\hline NM & $\mathrm{NM}$ & $\mathrm{PB}$ & $\mathrm{PB}$ \\
\hline NS & $\mathrm{NM}$ & PS & $\mathrm{PB}$ \\
\hline $\mathrm{ZE}$ & $\mathrm{NM}$ & $\mathrm{ZE}$ & $\mathrm{PM}$ \\
\hline PS & NM & PS & PB \\
\hline $\mathrm{PM}$ & $\mathrm{NM}$ & NS & $\mathrm{PB}$ \\
\hline $\mathrm{PB}$ & $\mathrm{NM}$ & NM & $\mathrm{PB}$ \\
\hline NB & NB & PVB & PVB \\
\hline NM & NB & PVB & PVB \\
\hline NS & NB & $\mathrm{PM}$ & PVB \\
\hline $\mathrm{ZE}$ & NB & $\mathrm{ZE}$ & $\mathrm{PB}$ \\
\hline PS & NB & $\mathrm{PM}$ & PVB \\
\hline $\mathrm{PM}$ & NB & NM & PVB \\
\hline
\end{tabular}

5.2. Sine Maneuver. Comparing with above experimental condition, assume that the vehicle runs on the dry asphalt

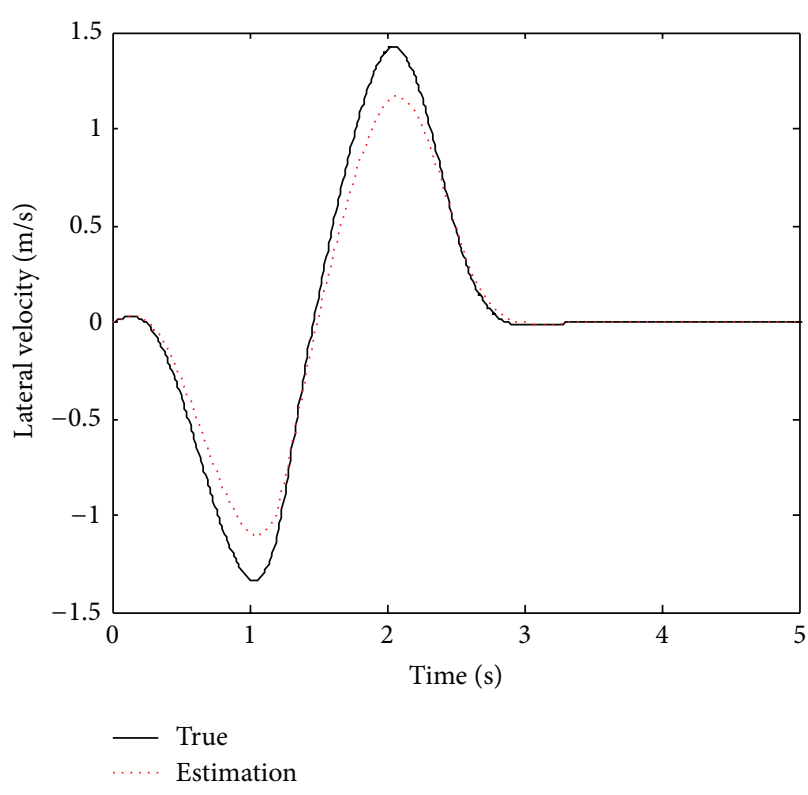

FIGURE 14: EKF observed value.

or concrete pavement with an initial speed of $20 \mathrm{~m} / \mathrm{s}$. The friction coefficient between tyre and road $\mu$ is 0.8 . The steering input signal with maximum value $4^{\circ}$ is shown in Figure 10. It is also shown that the front wheel angle compensation has a good effect on steering input. Figure 11 illustrates the sideslip angle responses of vehicles with control systems. It can be seen that, compared with the uncontrolled vehicle and only DYC, the sideslip angle responses have been improved effectively. As shown in Figure 12, the yaw rate response of a vehicle with the proposed control system can track the desired yaw rate. From Figure 13, it can be seen that the proposed control system needs smaller yaw control moment in contrast with DYC and it can be concluded that the integrated control system is able to achieve better stability in the smaller control energy. It can be seen that, from Figure 14, the lateral velocity estimated is close to true value and verifies the effectiveness of the proposed estimator.

\section{Conclusions}

The integrated control of AFS and DYC is proposed based on vehicle lateral velocity estimation. A fuzzy logic controller with two inputs and two outputs is designed to follow the desired yaw rate and sideslip angle. The estimation of the lateral velocity by EKF is to overcome the shortcoming that lateral velocity is difficult to be directly measured by instrumental sensors or measuring its value is of high cost. The simulation results show that the proposed control algorithm can enhance vehicle stability effectively compared with individual control system, DYC, and without control under different driving situation and road condition. 
TABLE 2: Values of vehicle parameters in simulation.

\begin{tabular}{lccccc}
\hline Mass and inertia & Value & Damping, stiffness & Value & Parameters & Value \\
\hline$m_{s}$ & $1167.5 \mathrm{~kg}$ & $C$ & $50000 \mathrm{~N} / \mathrm{m}$ & $1.436 \mathrm{~m}$ \\
$m$ & $1298.9 \mathrm{~kg}$ & $C_{\alpha}$ & $30000 \mathrm{~N} / \mathrm{m}$ & $a$ & $1 \mathrm{~m}$ \\
$I_{z}$ & $1627 \mathrm{~kg} \cdot \mathrm{m}^{2}$ & $C_{\phi}$ & $3511.6 \mathrm{~N} \cdot \mathrm{m} / \mathrm{rad} / \mathrm{sec}$ & $b$ & $1.454 \mathrm{~m}$ \\
$I_{x}$ & $498.9 \mathrm{~kg} \cdot \mathrm{m}^{2}$ & $K_{\phi}$ & $66185 \mathrm{~N} \cdot \mathrm{m} / \mathrm{rad}$ & $h$ & $0.533 \mathrm{~m}$ \\
$I_{w}$ & $2.1 \mathrm{~kg} \cdot \mathrm{m}^{2}$ & $R$ & $0.35 \mathrm{~m}$ & $e$ & $0.4572 \mathrm{~m}$ \\
\hline
\end{tabular}

\section{Acknowledgment}

The authors are grateful for supports by the Innovation Program of Shanghai Municipal Education Commission under Grant no. 12ZZ145 and Major Basic Research Development Program of Shanghai Municipal Science and Technology Commission under Grant no. 10JC1411600.

\section{References}

[1] Y. Shibahata, "Progress and future direction of Chassis control technology," Annual Reviews in Control, vol. 29, no. 1, pp. 151$158,2005$.

[2] K. Kitajima and H. Peng, "Hinf control for integrated side-slip, roll and yaw controls for ground vehicles," in Proceedings of the 5th International Symposium on Advanced Vehicle Control (AVEC '00), Ann Arbor, Mich, USA, 2000.

[3] M. Nagai, M. Shino, and F. Gao, "Study on integrated control of active front steer angle and direct yaw moment," JSAE Review, vol. 23, no. 3, pp. 309-315, 2002.

[4] W. Manning, D. Crolla, M. Brown, and M. Selby, "Coordination of chassis subsystems for vehicle motion control," in Proceedings of the 5th International Symposium on Advanced Vehicle Control (AVEC '00).

[5] B. Li and F. Yu, "Vehicle yaw dynamics through combining four-wheel-steering and differential braking," Transactions of the Chinese Society of Agricultural Machinery, vol. 39, no. 12, pp. $1-4,2008$.

[6] K. Guo and H. Ding, "The effect of yaw moment through differential braking under tire adhesion limit," Automotive Engineering, vol. 24, no. 2, p. 101, 2002.

[7] A. Y. Ungoren, H. Peng, and H. E. Tseng, "A study on lateral speed estimation methods," International Journal of Vehicle Autonomous Systems, vol. 2, no. 1-2, pp. 126-144, 2004.

[8] B. C. Chen and F. C. Hsieh, "Sideslip angle estimation using extended Kalman filter," Vehicle System Dynamics, vol. 46, supplement 1, pp. 353-364, 2008.

[9] U. Kiencke and L. Nielsen, Automotive Control Systems, Springer, Berlin, Germany, 2005.

[10] H. Dugoff, P. S. Fancher, and L. Segel, "An analysis of tire traction properties and their influence on vehicle dynamic performance," SAE, Article ID 700377, pp. 1219-1243, 1970.

[11] Y. Zhuoping and G. Xiaojie, "Review of vehicel state estimation problem under driving situation," Journal of Mechanical Engineering, vol. 45, no. 5, 2009.

[12] P. J. T. Venhovens and K. Naab, "Vehicle dynamics estimation using Kalman filters," Vehicle System Dynamics, vol. 32, no. 2, pp. 171-184, 1999.

[13] T. A. Wenzel, K. J. Burnham, M. V. Blundell, and R. A. Williams, "Dual extended Kalman filter for vehicle state and parameter estimation," Vehicle System Dynamics, vol. 44, no. 2, pp. 153-171, 2006.

[14] M. Nagai, M. Shino, and F. Gao, "Study on integrated control of active front steer angle and direct yaw moment," JSAE Review, vol. 23, no. 3, pp. 309-315, 2002.

[15] B. L. Boada, M. J. L. Boada, and V. Díaz, "Fuzzy-logic applied to yaw moment control for vehicle stability," Vehicle System Dynamics, vol. 43, no. 10, pp. 753-770, 2005.

[16] X. Yang, Z. Wang, and W. Peng, "Coordinated control of AFS and DYC for vehicle handling and stability based on optimal guaranteed cost theory," Vehicle System Dynamics, vol. 47, no. 1, pp. 57-79, 2009.

[17] M. J. L. Boada, B. L. Boada, A. Muñoz, and V. Díaz, "Integrated control of front-wheel steering and front braking forces on the basis of fuzzy logic," Proceedings of the Institution of Mechanical Engineers D, vol. 220, no. 3, pp. 253-267, 2006. 


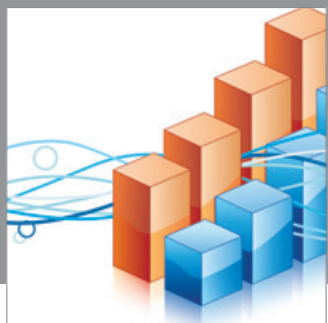

Advances in

Operations Research

mansans

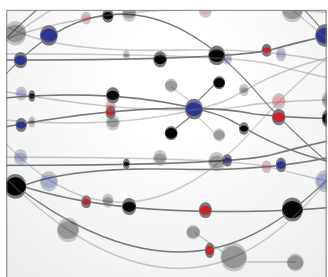

The Scientific World Journal
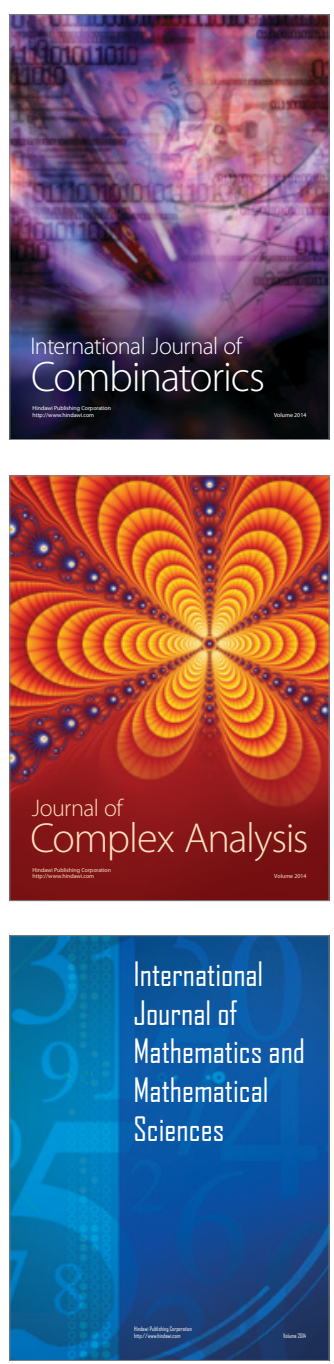
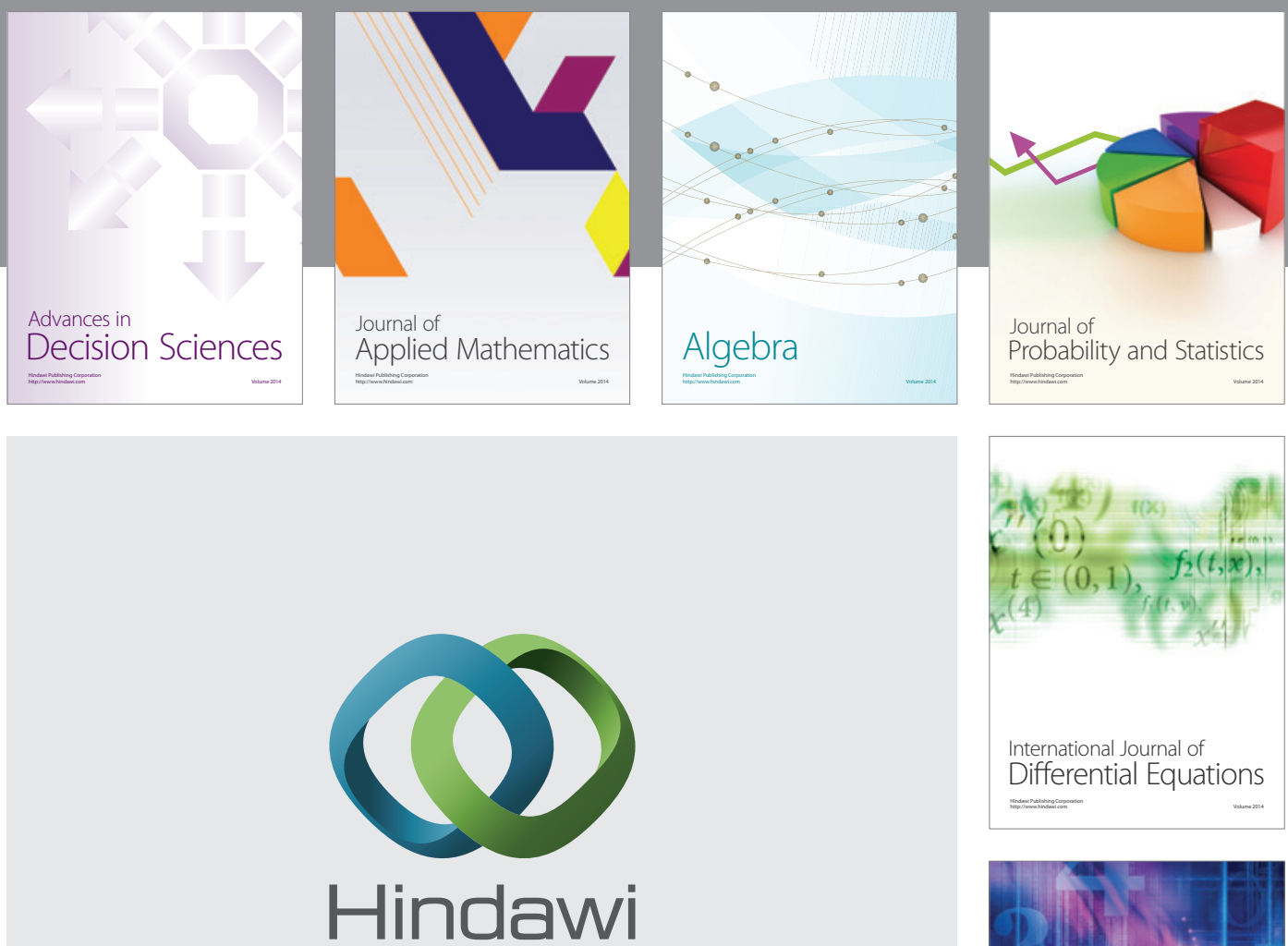

Submit your manuscripts at http://www.hindawi.com
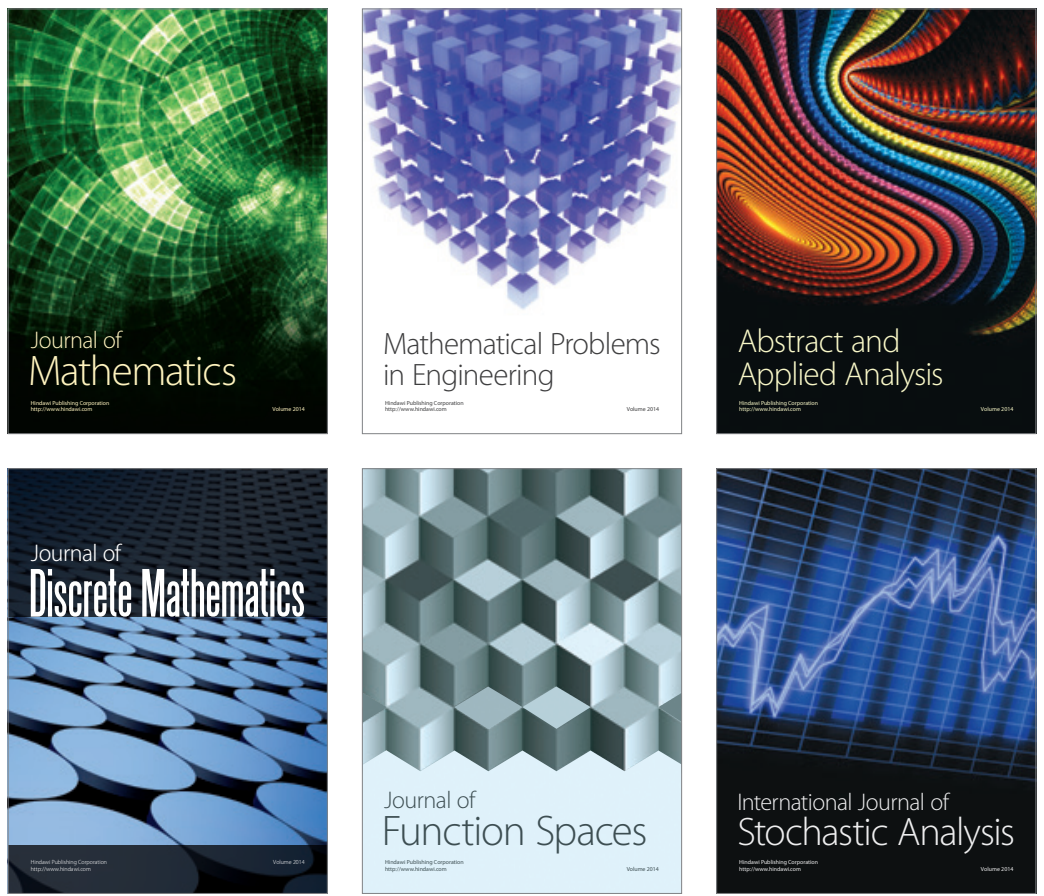

Journal of

Function Spaces

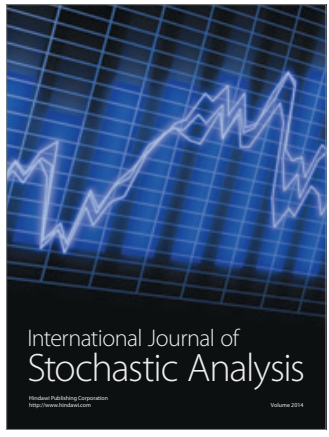

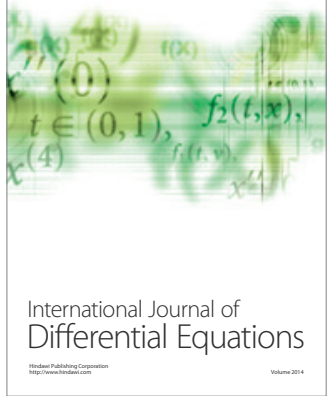
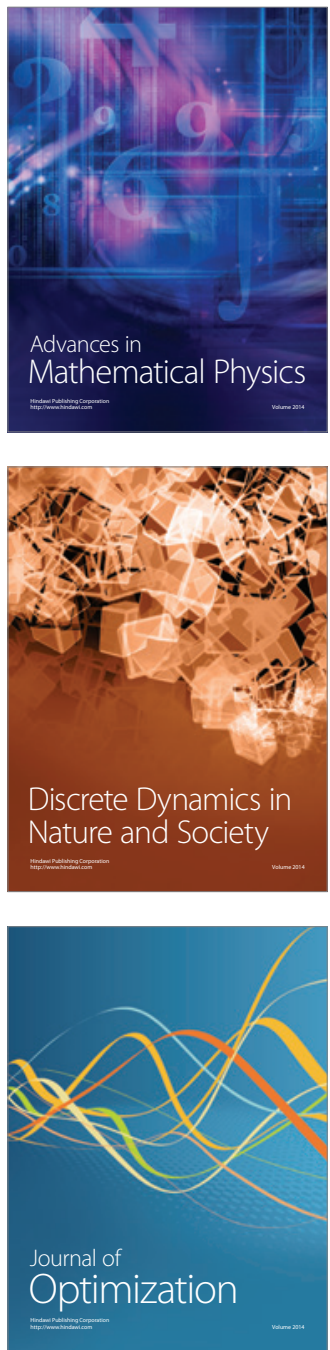